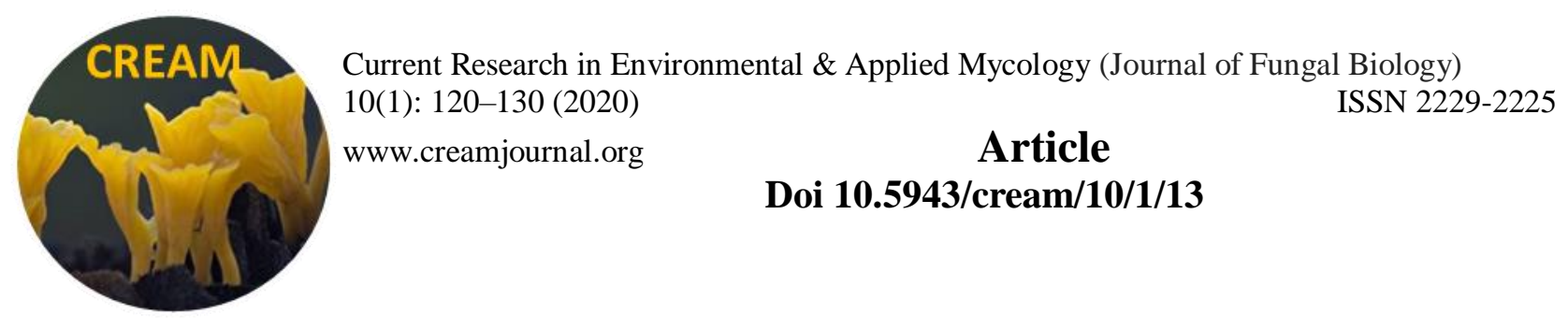

\title{
Cultivation of a wild strain of Auricularia cornea from Thailand
}

\author{
Thongklang $\mathrm{N}^{1,2 *}$, Keokanngeun $\mathrm{L}^{1}$, Taliam $\mathrm{W}^{1}$ and Hyde $\mathrm{KD}^{1,2}$ \\ ${ }^{1}$ Center of Excellence in Fungal Research, Mae Fah Luang University, Chiang Rai 57100, Thailand \\ ${ }^{2}$ School of Science, Mae Fah Luang University, Chiang Rai 57100, Thailand
}

Thongklang N, Keokanngeun L, Taliam W, Hyde KD 2020 - Cultivation of a wild strain of Auricularia cornea from Thailand. Current Research in Environmental \& Applied Mycology (Journal of Fungal Biology) 10(1), 120-130, Doi 10.5943/cream/10/1/13

\begin{abstract}
Auricularia (jelly fungi, ear mushroom) species are widely consumed, especially in Asia. Auricularia cornea is one of the cultivable species that was recently recorded from Thailand and is an edible mushroom used in Traditional Chinese Medicine. In this study, a strain of Auricularia cornea was collected from northern Thailand, confirmed with morphology, molecular data and was cultivated in the laboratory. Strain MFLUCC18-0346 was grown on PDA medium and spawn was prepared using Sorghum bicolor (sorghum) medium. Fruiting bodies were obtained by rubber sawdust bag cultivation. We found that the wild strain of $A$. cornea produced fruiting bodies at $25 \pm 1{ }^{\circ} \mathrm{C}$ and $75-85 \%$ humidity. The first primordia of $A$. cornea was produced on day 76 . The average yield of $A$. cornea was $242 \pm 37.52 \mathrm{~g}$ and the biological efficiency was $72.46 \pm 11.23 \%$ with six flushes in three months. The mushroom could be commercially cultivated; however, further research is needed to develop suitable agriculture wastes for increasing production yields and later the species could be introduced to Thai market for cultivation and medicinal use.
\end{abstract}

Key words - Auriculariaceae - Basidiomycota - fruiting test - medicinal mushroom - tropical mushroom

\section{Introduction}

Auricularia Bull. belongs to family Auriculariaceae of Basidiomycota with A. mesenterica (Dicks.: Fr.) Pers as the type species (Wu et al. 2015). The genus is commonly known as jelly fungi or ear mushrooms (Bandara et al. 2015). They are found in tropical, subtropical and temperate regions (Lowy 1952, Bandara et al. 2015, 2017a). Mushrooms of Auricularia are commercially cultivated and especially in China, for example, A. heimuer F. Wu, B.K. Cui \& Y.C. Dai and A. polytricha (Mont.) Sacc. (Du et al. 2011, Wu et al. 2014a, b). In addition, Auricularia species have nutrition and medical properties (De Silva et al. 2012a, b, 2013). A. auricula-judae (Bull.: Fr.) Queil. exhibits antioxidant activity (Ukai et al. 1983, Yuan et al. 1998, Fan et al. 2006, Kho et al. 2009, Cai et al. 2015, Choi et al. 2018). A. polytricha is also reported to exhibit antioxidant activities, anti-hypercholesterolemic effects and antimicrobial activities (Sun et al. 2010, Zhao et al. 2015, Avci et al. 2016).

Auricularia cornea Ehrenb. is a common edible and medicinal mushroom (Thawthong et al. 2014, Zhang et al. 2018a). The main characters of the species are: basidiocarp attached to substrate from corner or center, short stalks, light brown to dark brown and undulate margin, ridges and veins present and shorter abhymenial hairs than A. nigricans (Bandara et al. 2017a). Bandara et al. 
(2017a) reported $A$. cornea as a new record from Thailand based on morphological characters and phylogenetic evidences. The potential medicinal benefits of $A$. cornea have been studied in several reports. The mushroom showed antioxidant activity, reduce alcoholic liver diseases (ALD), reduce blood fat, exhibited anticancer activities and enhanced immune system (De Silva et al. 2013, Kozarski et al. 2015, Wang et al. 2018, Sajon et al. 2018, Zhang et al. 2018a).

In Thailand, only A. auricula-judae and A. polytricha are cultivated commercially (Thawthong et al. 2014). In addition, Bandara et al. (2017b) reported that A. thailandica, a new species to Thailand produced fruiting bodies in bag cultivation. Several studies reported the optimal conditions for cultivation of A. cornea in China (Wang et al. 2015, Zhang et al. 2017, 2018b). However, there has been no report of the cultivation of Thai strain. Therefore, in this study, we

report on a Thai strain of $A$. cornea as optional mushroom that can be cultivated in Thailand. It is hoped to be able to introduce the new native edible mushroom that could be domesticated in Thailand.

\section{Materials \& Methods}

\section{Mushroom strain}

A Thai strain of Auricularia cornea (LK13) was collected from Mae Suay, Chiang Rai, Thailand by L. Keokanngeun in 2017. The strain was isolated by spore isolation and subcultured on PDA media and incubated at $25^{\circ} \mathrm{C}$ for 14 days. The strain collection and dry specimen are deposited at Mae Fah Luang University Culture Collection (MFLUCC 18-0346) and Mae Fah Luang University Herbarium (MFLU 19-0797).

\section{Species confirmation}

Morphological characters of Thai A. cornea were recorded. Macro morphological characters were described from fresh specimens in the laboratory. Colour notations of Kornerup \& Wanscher (1978) are used. Micro morphological characters were obtained from free-hand sections of the dried specimens. The tissues were mounted in $\mathrm{H}_{2} \mathrm{O}$ and $5 \%$ aqueous $\mathrm{KOH}$ solution and Congo red was used for highlighting all structures. Measurements of microscopic characters were obtained based on at least 20 measurements. $\bar{x}$ (x-bar) represents the sample mean. The quotient (Q), the length/width ratio was also calculated to indicate the basidiospore shape.

Dried basidiocarps of cultivated A. cornea were used for molecular analysis. DNA was extracted with Biospin Fungus Genomic DNA extraction kit, BSC14S1 (Bioer Technology Co., Ltd. Bio-Tek, Hangzhou, P.R. China) following the manufacturer's protocol. DNA amplification was performed in the Applied Biosystems Veriti Thermal Cycler in a total volume of $25 \mu \mathrm{lusing}$ primers for ribosomal DNA regions (ITS4/ ITS5) and following the protocol of White et al. (1990). PCR mixtures contained $1 \mu \mathrm{l}$ of each primer, $9.5 \mu \mathrm{l}$ of double-distilled water, $12.5 \mu \mathrm{l}$ of master mix (DNA polymerase $0.3 \mu 1,12.5 \mu 1$ of $2 \times$ PCR buffer with $2.5 \mu 1$ of dNTPs) and 100-500 ng of DNA template. Sequencing was performed on an ABI 3730 XL DNA analyzer (Applied Biosystems) at Shuo Yang Technology Co., Ltd, Kunming, China. The newly generated sequence was submitted to GenBank, and its accession number is listed in Table 1. The sequence data was assembled using BioEdit v. 7.2.5 (Hall 1999) and subjected to a BLAST search (https://blast.ncbi.nlm.nih.gov/Blast.cgi) to find the closest matches. Reference sequence data were downloaded and were automatically aligned using default settings in MAFFT v. 7 (Katoh \& Toh 2008; http://mafft.cbrc.jp/alignment/server/). The ITS dataset was prepared and manually adjusted using BioEdit where necessary. PAUP v. 4.0b10 (Swofford 2002) was used to conduct the maximum parsimony analysis (MP). Gaps were treated as missing data and ambiguously aligned regions were excluded. Trees were inferred using the heuristic search option with tree bisection reconnection (TBR) branch swapping and 1,000 random sequence additions. Maxtrees were set up to 5000, branches of zero length were collapsed and all multiple parsimonious trees were saved. Descriptive tree statistics for parsimony (tree length [TL], consistency index [CI], retention index $[\mathrm{RI}]$, rescaled consistency index [RC] and homoplasy index [HI]) were calculated for trees 
generated under different optimality criteria. The robustness of the most parsimonious trees was evaluated by 1000 bootstrap replications resulting from maximum parsimony analysis (Hillis \& Bull 1993). Kishino-Hasegawa tests (KHT) (Kishino \& Hasegawa 1989) were performed to determine whether the trees were significantly different. Phylograms were visualized with FigTree v1.4.0 program (Rambaut 2012) and in Adobe Illustrator CS5 (Version 15.0.0, Adobe, San Jose, $\mathrm{CA})$.

Table 1 Samples and accession numbers that used for species confirmation in phylogenetic analysis. Sequence generated in this study is in blue.

\begin{tabular}{|c|c|c|c|}
\hline Taxon name & Herbarium code & Culture code & $\begin{array}{l}\text { GenBank accession } \\
\text { number (ITS) }\end{array}$ \\
\hline \multirow[t]{4}{*}{ A. americana } & Dai 13636 & - & KM396765 \\
\hline & Cui 11657 & - & KT152095 \\
\hline & Cui 11509 & - & KT152094 \\
\hline & Cui 9887 & - & KM396762 \\
\hline \multirow[t]{3}{*}{ A. angiospermarum } & Cui 12360 & - & KT152097 \\
\hline & HHB 11037 & - & KT152098 \\
\hline & TJV9312SP & - & KT152096 \\
\hline \multirow[t]{2}{*}{ A. asiatica } & BBH1 & - & KX621159 \\
\hline & BBH895 & - & KX621160 \\
\hline \multirow[t]{3}{*}{ A. auricula-judae } & Dai 13549 & - & KM396770 \\
\hline & MT7 & - & KM396771 \\
\hline & Dai 13210 & - & KM396769 \\
\hline \multirow{3}{*}{ A. brasiliana } & URM 83468 & - & KP729272 \\
\hline & URM 83482 & - & KP729273 \\
\hline & URM 84563 & - & KP729274 \\
\hline \multirow{12}{*}{ A. cornea } & MFLU 13-0403 & - & KX621145 \\
\hline & MFLU 16-2104 & - & KX621144 \\
\hline & MFLU 16-2107 & - & KX621142 \\
\hline & MFLU 16-2108 & - & KX621140 \\
\hline & MFLU 16-2109 & - & KX621143 \\
\hline & MFLU 16-2110 & - & KX621141 \\
\hline & MFLU 19-0797 & MFLUCC 18-0346 & MK696312 \\
\hline & - & AG6 & KX022015 \\
\hline & - & AG1547 & KX022016 \\
\hline & - & Dai 12587 & KX022012 \\
\hline & - & Dai 13547 & KX022013 \\
\hline & - & Dai 15336 & KX022014 \\
\hline A. delicata & - & USJ54470 & AF291269 \\
\hline A. fibrillifera & F234519 & - & KP765610 \\
\hline \multirow[t]{3}{*}{ A. fuscosuccinea } & MW 530 & - & AF291270 \\
\hline & PR 1378 & - & KM396774 \\
\hline & PR 1496 & - & KM396775 \\
\hline \multirow[t]{3}{*}{ A. heimuеr } & - & Dai 2291 & KM396785 \\
\hline & - & Dai 13503 & KM396789 \\
\hline & - & Dai 13765 & KM396793 \\
\hline \multirow[t]{2}{*}{ A. mesenterica } & Kytovuori 89-333 & - & KP729284 \\
\hline & Miettinen 12680 & - & KP729286 \\
\hline A. minor & LE 296424 & - & KJ698434 \\
\hline A. minutissima & - & Dai 14880 & KT152103 \\
\hline \multirow[t]{2}{*}{ A. nigricans } & - & Ahti36234 & KM396802 \\
\hline & - & TJY93242 & KM396803 \\
\hline A. orientalis & BJFC & Dai 14875 & KP729270 \\
\hline
\end{tabular}


Table 1 Continued.

\begin{tabular}{llll}
\hline Taxon name & Herbarium code & Culture code & $\begin{array}{l}\text { GenBank accession } \\
\text { number (ITS) }\end{array}$ \\
\hline & - & Dai 1831 & KP729271 \\
A. scissa & - & Ahti49388 & KM396805 \\
& - & DR777 & KM396804 \\
A. subglabra & TENN058100 & TFB10405 & JX065161 \\
A. thailandica & MFLU 13-0410 & - & KR336693 \\
A. tibetica & BJFC017181 & Cui 12267 & KT152106 \\
& - & Cui 12268 & KT152107 \\
& - & Cui 12266 & KT152105 \\
A. villosula & - & Cui 11207 & KM396811 \\
& - & Cui 6760 & KM396809 \\
Tremella globispora & CBS 6972 & Dai 13450 & KM396812 \\
Tremella & CBS 6973 & & AF444432 \\
mesenterica & & & AF444433 \\
\hline
\end{tabular}

\section{Spawn production}

Sorghum bicolor (sorghum) grains were used for spawn production (Thongklang \& Luangharn 2016). Grains were washed and soaked for overnight, then water was drained off, and grains were boiled for 15 minutes. One hundred grams of grains were contained in bottles, autoclaved at $121^{\circ} \mathrm{C}$ for 15 minutes and left to cool. The bottles were inoculated with three mycelial plugs of approximately $0.5 \mathrm{~cm}$ diam.. Inoculated bottles were incubated in the dark at $25^{\circ} \mathrm{C}$ during 21 days.

\section{Fruiting test}

A fruiting test of the Thai wild strain of A. cornea was carried out with five replicates. Rubber sawdust was used as the main substrate and was mixed (w/w) with $5 \%$ of rice bran, $1 \%$ of spent brewery grain, $1 \%$ of glutinous rice flour, $1 \%$ of pumice sulfate and $1 \%$ of calcium carbonate. All substrate supplements were manually mixed with $70 \%$ moisture. The mixture $(800 \mathrm{~g})$ was packed into polypropylene bags then capped with a plastic ring and lid. The sawdust bags were sterilized at $121^{\circ} \mathrm{C}$ for 45 minutes. After the temperature cooled to $25^{\circ} \mathrm{C}, 50 \mathrm{~g}$ of spawn was inoculated into the sawdust bags under aseptic conditions. The bags were incubated at $25 \pm 1^{\circ} \mathrm{C}$ in the dark, for 90 days. For the fruiting phase, the same temperature and $75-85 \%$ humidity were used.

\section{Yield data and statistical analysis}

The fruiting bodies of $A$. cornea were manually harvested, counted and weighed daily. The mushroom yields were recorded for 55 days after first primordia appeared. Yield data and biological efficiency (B.E.) of A. cornea were calculated. Yield data means total weight of fresh mushroom per kilogram of substrate (Royse 2010, Llarena-Hernández et al. 2011, Thongklang et al. 2014), biological efficiency (B.E.) means weight of harvest/weight of dry substrate) x $100 \%$ (Onyango et al. 2011, Abdul Razak et al. 2013, Liang et al. 2019).

\section{Results}

\section{Confirmation of cultivated species}

A wild Thai Auricularia strain that produced fruiting bodies was confirmed to A. cornea based on morphological characters and phylogenetic analysis. 
Basidiocarp - 1.3-4.5 cm, attached to substrate from center, short stalks, undulate margin; abhymenial surface brown, 7F6 to brown; hymenial surface violet brown, 11F6, ridges and viens absent.

Internal features - thickness 2260-2410 $\mu \mathrm{m}$; medulla present; abhymenial hairs densely arranged, hyaline, blunt tip, thin or thick walled, wall thickness $1.5-3 \mu \mathrm{m}$, hair bases $7-9 \mu \mathrm{m}$ wide; zona pilosa 130-210 $\mu \mathrm{m}$; zona compacta 50-65 $\mu \mathrm{m}$; zona subcompacta superioris 190-260 $\mu \mathrm{m}$; zona laxa superioris $160-290 \mu \mathrm{m}$; medulla $230-300 \mu \mathrm{m}$; zona laxa inferioris $490-700 \mu \mathrm{m}$; zona subcompacta inferioris 125-155 $\mu \mathrm{m}$; hymenium 57-95 $\mu \mathrm{m}$; basidia 80-97 × 4-6 $\mu \mathrm{m}$, cylindrical, blunt or tapered ends; basidiospores smooth walled, allantoid, hyaline, (12.6)13.5-15.0(15.6) $\times$ (5.4)5.7-6.3(6.7) $\mu \mathrm{m}, \bar{x}=14.3 \times 6.0 \mu \mathrm{m}, \mathrm{Q}=2.1-2.7$.

Material examined - THAILAND, Chiang Rai: Mae Suay, on dead wood, 28 September 2017, Lattana Keokanngeun, LK13 )MFLU 19-0797(.

The final alignment of ITS dataset comprises 55 strains including the outgroups. The dataset consists 537 characters including gaps, of which 311 characters are constant, 137 characters are parsimony-informative and 89 variable characters are parsimony-uninformative. The parsimony analysis resulted in one most parsimonious tree with a length of 498 steps $(\mathrm{CI}=0.643, \mathrm{RI}=0.860$, $\mathrm{RC}=0.552$, HI=0.357). MFLU 19-0797 (LK13) clustered with the strains of A. cornea with strong bootstrap support (Fig. 2).

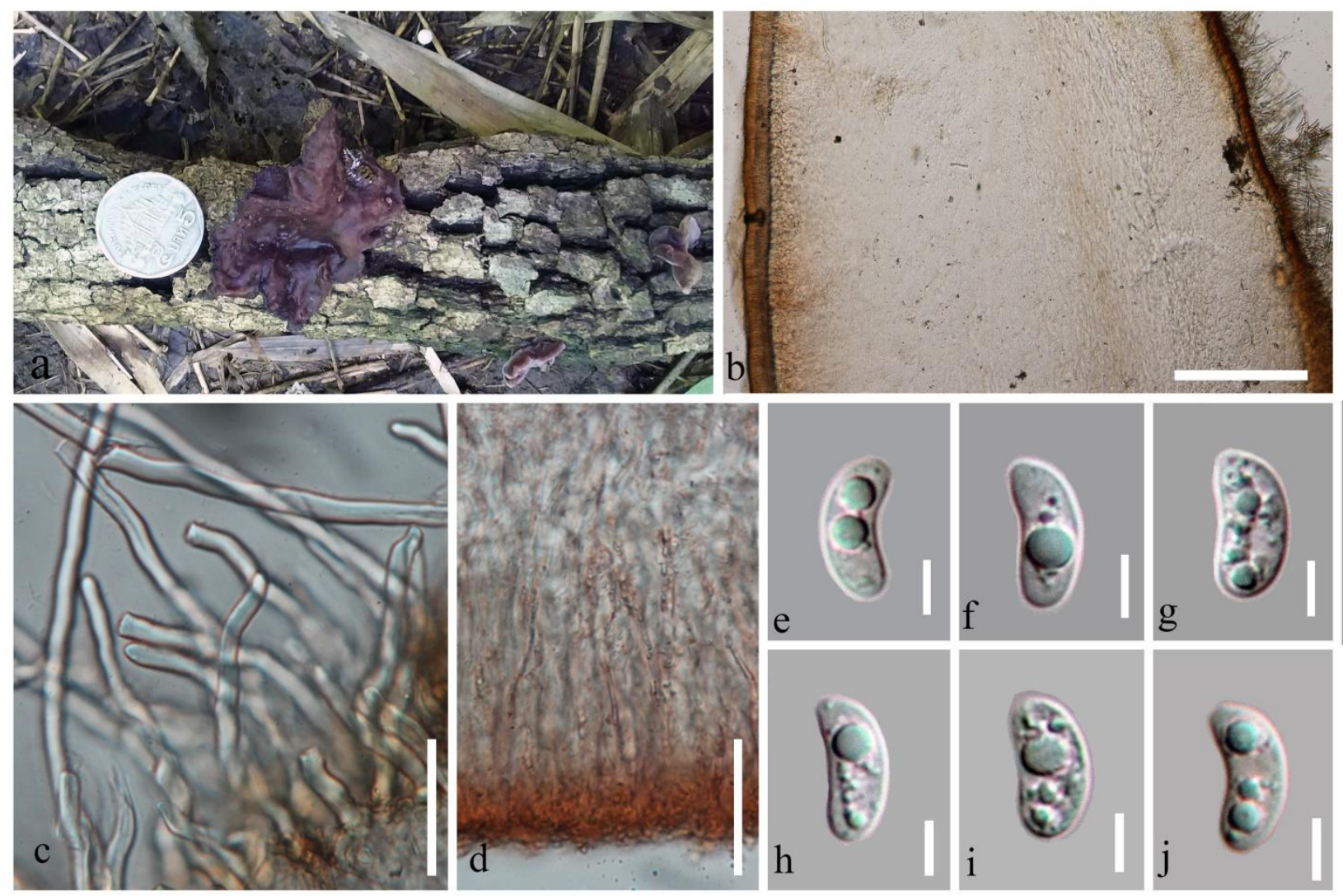

Fig. 1 - Auricularia cornea )MFLU 19-0797, LK13(. a Basidiomes. b Cross-section of the fruiting body. c Abhymenial hairs. d Close-up of hymenial layer. e-j Basidiospores. Scale bars: $b=500$ $\mu \mathrm{m}, \mathrm{c}=50 \mu \mathrm{m}, \mathrm{d}=25 \mu \mathrm{m}, \mathrm{e}-\mathrm{j}=5 \mu \mathrm{m}$.

\section{First cultivation of Thai Auricularia cornea}

Cultivation of a wild strain of A. cornea MFLUCC18-0346 (LK13) was carried out with five replicates. The mycelium full colonized the substrate on day 65 . The primordia were appeared on day 76. The average yield was $242 \pm 37.52 \mathrm{~g}$ with six flushes in 55 days after first primordia appeared (Fig. 3). Yield data and biological efficiency are given in Table 2. In addition, the yield of 
the first flush was the lowest (3.59\%), with the average weight of $12 \pm 5.70 \mathrm{~g}$, while the highest $(22.75 \%)$ was in the flush six and the average weight was $76 \pm 23.02 \mathrm{~g}$ (Table 3 ).

Table 2 Comparison first flush yields of Thai A. cornea

\begin{tabular}{ll}
\hline \multicolumn{1}{c}{ Content } & \multicolumn{1}{c}{ Thai A. cornea } \\
\hline Primodia after inoculation (days) & 76 \\
Numbers of flush & 6 \\
Average weight $(\mathrm{g} / \mathrm{bag})$ & $242 \pm 37.52$ \\
Yield data* $\left(\mathrm{g} / \mathrm{kg}^{-1}\right)$ & 302.5 \\
Biological efficiency (B.E.) & $72.46 \pm 11.23$ \\
\hline
\end{tabular}

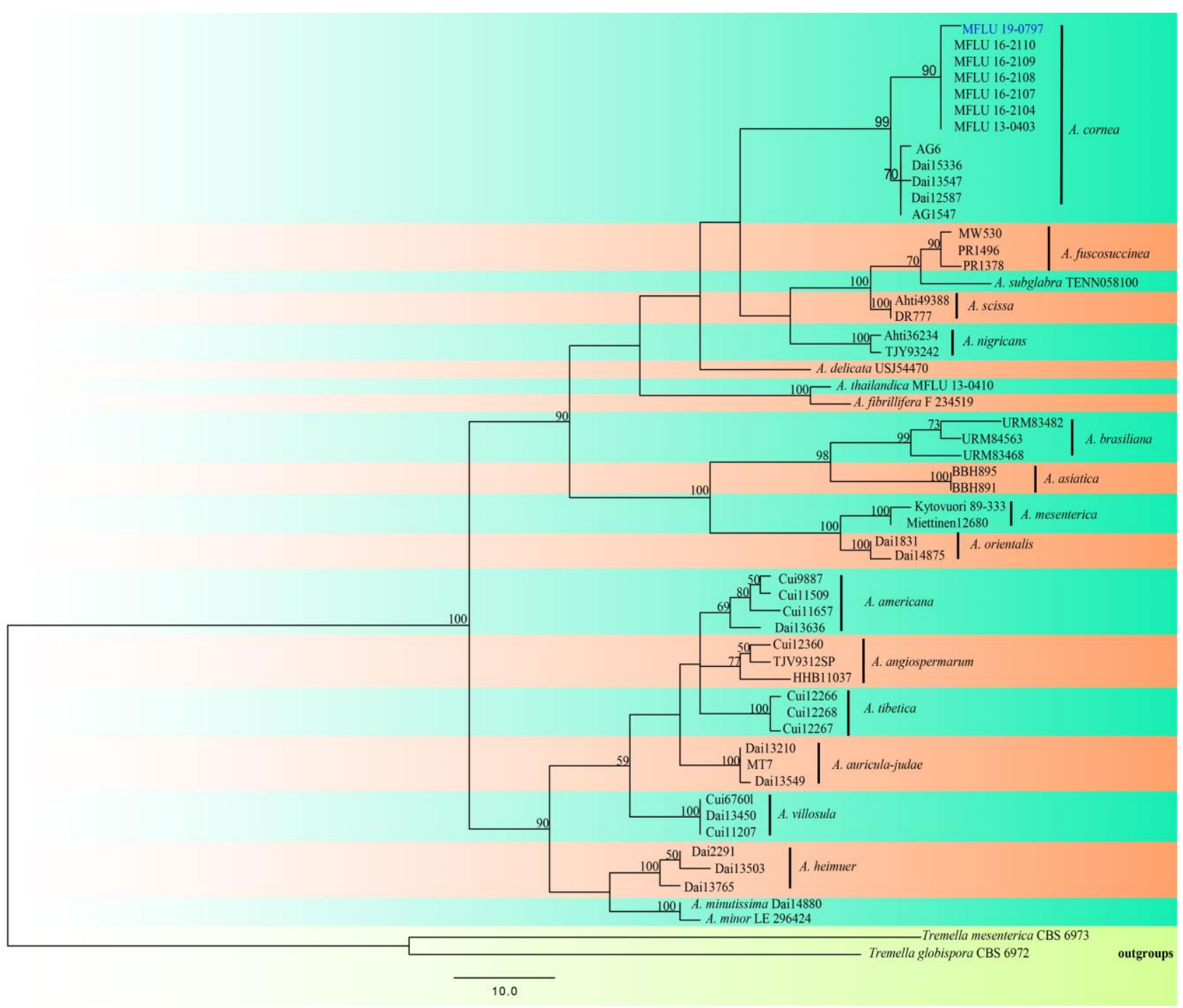

Fig. 2 - Phylogenetic tree generated by maximum parsimony analysis of ITS sequences of Auricularia. Original code of specimens and species names are shown. Bootstrap support values $>50 \%$ are indicated above each node. Tree is rooted with Tremella globispora and Tremella mesenterica. Specimen used in this study is in blue.

Table 3 Comparison mushroom yield in each flushe (5 replications)

\begin{tabular}{cll}
\hline Flush & Average weight $(\mathbf{g})$ & Biological efficiency (B.E.) \\
\hline 1 & $12 \pm 5.70$ & $3.59 \%$ \\
2 & $28 \pm 8.37$ & $8.38 \%$ \\
\hline
\end{tabular}


Table 3 Continued.

\begin{tabular}{cll}
\hline Flush & \multicolumn{1}{c}{ Average weight (g) } & \multicolumn{1}{c}{ Biological efficiency (B.E.) } \\
\hline 3 & $54 \pm 16.73$ & $16.17 \%$ \\
4 & $40 \pm 21.21$ & $11.98 \%$ \\
5 & $32 \pm 8.37$ & $9.58 \%$ \\
6 & $76 \pm 23.02$ & $22.75 \%$ \\
\hline
\end{tabular}

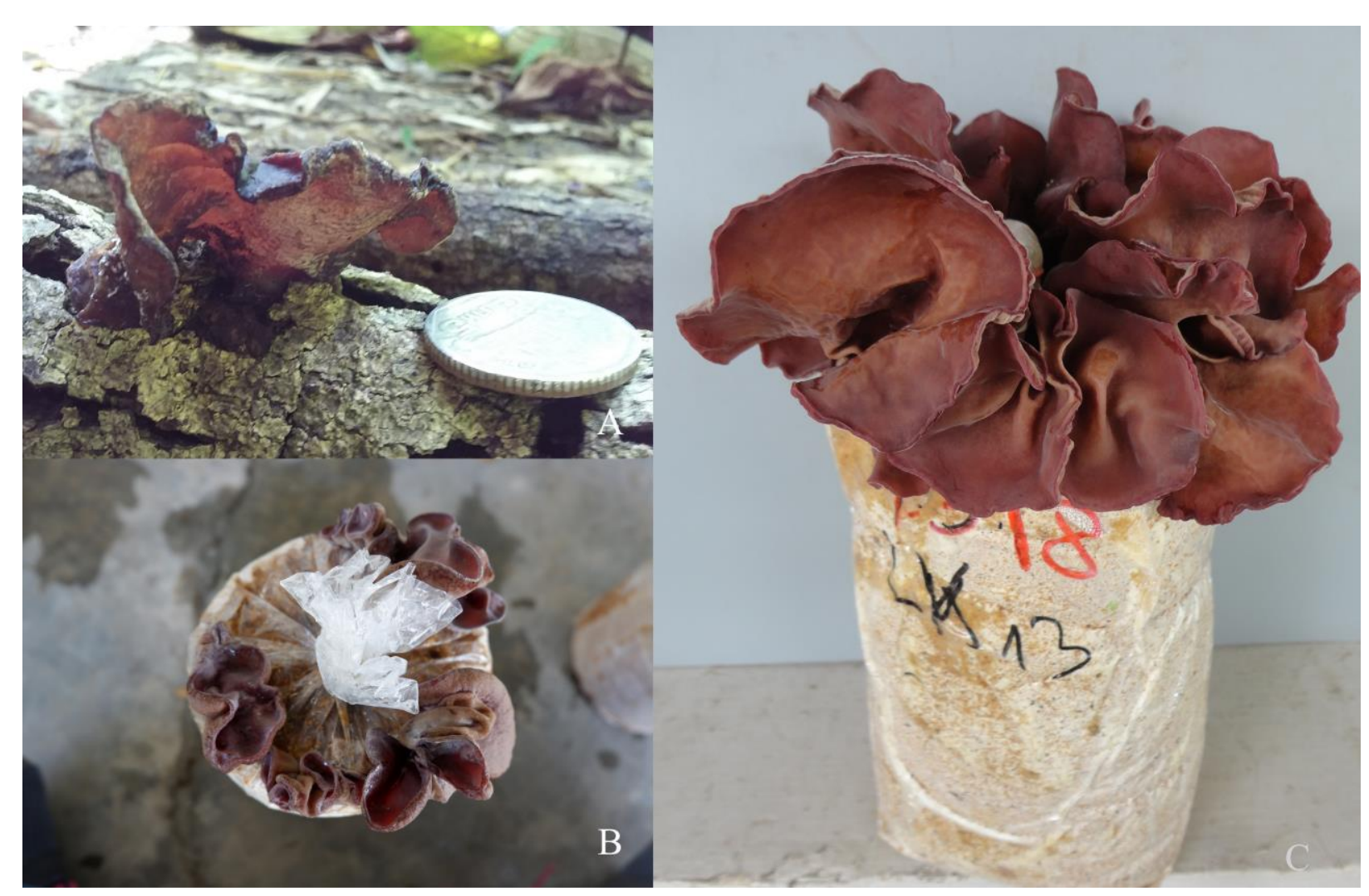

Fig. 3 - A Auricularia cornea from wild. B, C Cultivated basidiocarps of A. cornea (MFLUCC180346).

\section{Discussion}

There are more than 30,000 species of Basidiomycota while 137 species have been cultivated. (Kirk et al. 2008, Thawthong et al. 2014). However, few mushrooms are commercially cultivated in Thailand (Thawthong et al. 2014). Thailand has a rich mushroom biodiversity. Recently, 93\% of mushrooms collected from northern Thailand were shown to be new to science (Hyde et al. 2018). Wild mushrooms have been collected from Thailand and several species are potentially cultivatable and have medicinal properties. For example, wild strains of Agaricus flocculosipes, A. subrufescens, A. subtilipes, Auricularia thailandica, Lepista sordida, Macrolepiota dolichaula and Pleurotus giganteus, were successfully cultivated in the laboratory experiments (Klomklung et al. 2012, Rizal et al. 2016, Thongklang et al. 2014, 2016, Bandara et al. 2017b, Thongbai et al. 2017).

Auricularia cornea was introduced as a new record to Thailand by Bandara et al. (2017a). It has been reported as a food in Congo (Kamalebo et al. 2018) and in China (Dai et al. 2015). To our knowledge, only A. auricula and A. polytricha have been cultivated in Thailand (Thawthong et al. 2014). The present study introduces a new wild strain of $A$. cornea from Thailand.

Auricularia is normally cultivated using sawdust as the main substrate (Abdul Razak et al. 2013, Bandara et al. 2017b, Liang et al. 2019). Wang et al. (2016) reported that rubber sawdust is suitable for cultivation of wild A. delicata from China, and our result indicated this is useful for the Thai A. cornea, which yielded six flushes of first crop production. 
Agricultural wastes can also be used as the main substrates to grow Auricularia species. This is an important finding as an alternative way to grow mushrooms and many of them produced higher yields than sawdust alone. For example, Abdul Razak et al. (2013) reported that the biological efficiency (B.E.) of $A$. polytricha grow in sawdust + oil palm frond + spent grain and sawdust + empty fruit bunch + spent grain were $288.9 \%$ and $260.7 \%$, respectively while in sawdust alone was $105.9 \%$. Liang et al. (2019) also reported that $A$. polytricha grown in sawdust + panicum repens stalk gave better yields than sawdust alone, the B.E. of both substrates were $148.12 \%$ and $99.49 \%$, respectively. In addition, maize cobs + wheat bran as main substrate was reported as suitable to grow the mushrooms A. auricular brown and black strains in Kenya (Onyango et al. 2011). In fruiting trials of Thai $A$. cornea, the productivity (B.E.) was low $(72.46 \pm 11.23 \%)$ in sawdust substrate. Therefore, further work will be carried out to develop suitable conditions for grow the Thai $A$. cornea by using local agricultural waste in laboratory and at the industry scale. Moreover, nutrition and biological characterization and active compounds should be investigated.

Mushrooms are not only used as food but can be used as traditional medicines and used in cosmetics formulas (De Silva et al. 2013, Hyde et al. 2019). Domestication of novel species or new strains of mushrooms have recently been a hot issue (Hyde et al. 2019). However, the success of growing new strains depends on economical and biological factors (Thawthong et al. 2014). Several reports on A. cornea indicate that it is a nutritive and medicinal mushroom (Kozarski et al. 2015, Wang et al. 2018, Zhang et al. 2018a, Li et al. 2019). Thus, the Thai strain is likely to be a good choice for domestication and cultivation. It could help the livelihood of Thai farmer to grow alternative potential mushrooms.

\section{Acknowledgements}

We gratefully acknowledge Mae Fah Luang University and National Research Council of Thailand for grant entitle "Thailands fungal diversity, solving problems and creating biotechnological products" subproject "Cultivation of Auricularia thailandica sp. nov., and other species from Thailand" (grant No. 61201321016) for financial support and Miss Napalai Chaiwan for molecular analysis.

\section{References}

Abdul Razak DL, Abdullah N, Johari NMK, Vikineswary S. 2013 - Comparative study of mycelia growth and sporophore yield of Auricularia polytricha (Mont) Sacc on selected palm oil wastes as fruiting substrate. Applied Microbiology and Biotechnology 97, 3207-3213, Doi 10.1007/s00253-012-4135-8.

Avci E, Cagatay G, Avci GA, Suiçmez M, Cevher SC. 2016 - An Edible Mushroom with Medicinal Significance; Auricularia polytricha. Hittite Journal of Science and Engineering 3, 111-116, Doi 10.17350/HJSE19030000040.

Bandara AR, Chen J, Karunarathna S, Hyde KD, Kakumyan P. 2015 - Auricularia thailandica sp. nov. (Auriculariaceae, Auriculariales) a widely distributed species from southeastern Asia. Phytotaxa 208, 147-156, Doi 10.11646/phytotaxa.208.2.3.

Bandara AR, Karunarathna SC, Mortimer PE, Hyde KD et al. 2017b - First successful domestication and determination of nutritional and antioxidant properties of the red ear mushroom Auricularia thailandica (Auriculariales, Basidiomycota). Mycological Progress 16, 1029-1039, Doi 10.1007/s11557-017-1344-7.

Bandara AR, Karunarathna SC, Phillips AJ, Mortimer PE et al. 2017a - Diversity of Auricularia (Auriculariaceae, Auriculariales) in Thailand. Phytotaxa 292, 19-34, Doi 10.11646/phytotaxa.292.1.2.

Cai M, Lin Y, Luo YL, Liang HH, Sun PL. 2015 - Extraction, antimicrobial, and antioxidant activities of crude polysaccharides from the Wood Ear medicinal mushroom Auricularia auricula-judae (higher Basidiomycetes). International Journal of Medicinal Mushrooms 17, 591-600, Doi 10.1615/IntJMedMushrooms.v17.i6.90. 
Choi YJ, Park IS, Kim MH, Kwon B et al. 2018 - The medicinal mushroom Auricularia auriculajudae (Bull.) extract has antioxidant activity and promotes procollagen biosynthesis in HaCaT cells. Natural Product Research, 1-4, Doi 10.1080/ 14786419.2018.1468332.

Dai YC, Cui BK, Si J, He SH et al. 2015 - Dynamics of the worldwide number of fungi with emphasis on fungal diversity in China. Mycological Progress 14, article 62,

Doi 10.1007/s11557-015-108405.

De Silva DD, Rapior S, Fons F, Bahkali AH, Hyde KD. 2012a - Medicinal mushrooms in supportive cancer therapies: an approach to anti-cancer effects and putative mechanism of action. Fungal Diversity 55, 1-35, Doi 10.1007/s13225-012-0151-3.

De Silva DD, Rapior S, Hyde KD. 2012b - Medicinal mushrooms in prevention and control of diabetes mellitus. Fungal Diversity 56, 1-29, Doi 10.1007/s13225-012-0187-4.

De Silva DD, Rapior S, Sudarman E, Stadler M et al. 2013 - Bioactive metabolites from macrofungi: ethnopharmacology, biological activities and chemistry. Fungal Diversity 62, 140, Doi 10.1007/s13225-013-0265-2.

Du P, Cui BK, Dai YC. 2011 - Genetic diversity of wild Auricularia polytricha in Yunnan Province of South-western China revealed by sequence-related amplified polymorphism (SRAP) analysis. Journal of Medicinal Plants Research 5, 1374-1381.

Fan L, Zhang S, Yu L, Ma L. 2006 - Evaluation of antioxidant property and quality of breads containing Auricularia auricula polysaccharide flour. Food Chemistry 101, 1158-1163, Doi 10.1016/j.foodchem.2006.03.017.

Hall TA. 1999 - BioEdit: a user-friendly biological sequence alignment editor and analysis program for Windows 95/98/NT. Nucleic Acids Symposium Series 41, 95-98.

Hyde KD, Norphanphoun C, Chen J, Dissanayake AJ et al. 2018 - Thailand's amazing diversity: up to $96 \%$ of fungi in northern Thailand may be novel. Fungal Diversity 93, 215-239, Doi 10.1007/s13225-018-0415-7.

Hyde KD, Xu J, Rapior S, Jeewon R et al. 2019 - The amazing potential of fungi, 50 ways we can exploit fungi industrially. Fungal Diversity 97, 1-136, Doi 10.1007/s13225-019-00430-9.

Hillis DM, Bull JJ. 1993 - An empirical test of bootstrapping as a method for assessing confidence in phylogenetic analysis. Systematic Biology 42, 182-192, Doi 10.1093/sysbio/42.2.182.

Kamalebo HM, Malale HNSW, Ndabaga CM, Degreef J, De Kesel A. 2018 - Uses and importance of wild fungi: traditional knowledge from the Tshopo province in the Democratic Republic of the Congo. Journal of Ethnobiology and Ethnomedicine 14, article 13,

Doi 10.1186/s13002-017-0203-6.

Katoh K, Toh H. 2008 - Recent developments in the MAFFT multiple sequence alignment program. Briefings in Bioinformatics 9, 276-285, Doi 10.1093/bib/bbn013.

Kho YS, Vikineswary S, Abdullah N, Kuppusamy UR, Oh HI. 2009 - Antioxidant capacity of fresh and processed fruit bodies and mycelium of Auricularia auricula-judae (Fr.) Quél. Journal of Medicinal Food 2, 167-174, Doi 10.1089/jmf.2007.0568.

Kirk PM, Cannon PF, Minter DW, Stalpers JA. 2008 - Dictionary of the fungi (10th ed.). Cromwell Press, Trowbridge.

Kishino H, Hasegawa M. 1989 - Evaluation of the maximum likelihood estimate of the evolutionary tree topologies from DNA sequence data. Journal of Molecular Evolution 29, 170-179.

Klomklung N, Karunarathna SC, Chukeatirote E, Hyde KD. 2012 - Domestication of wild strain of Pleurotus giganteus. Sydowia 60, 39-53.

Kornerup A, Wanscher JH. 1978 - Methuen Handbook of Colour. Eyre Methuen, London.

Kozarski M, Klaus A, Jakovljevic D, Todorovic N et al. 2015 - Antioxidants of edible mushrooms. Molecules 20, 19489-19525, Doi 10.3390/molecules201019489.

Li X, Yan L, Li Q, Tan H et al. 2019 - Transcriptional profiling of Auricularia cornea in selenium accumulation. Scientific Reports 9, article 5641. Doi 10.1038/s41598-019-42157-2.

Liang CH, Wu CY, Lu PL, Kuo YC, Liang ZC. 2019 - Biological efficiency and nutritional value of the culinary-medicinal mushroom Auricularia cultivated on a sawdust basal substrate 
supplement with different proportions of grass plants. Saudi Journal of Biological Sciences 26, 263-269. Doi 10.1016/j.sjbs.2016.10.017.

Llarena-Hernández RC, Largeteau M, Farnet AM, Minvielle N et al. 2011 - Phenotypic variability in cultivars and wild strains of Agaricus brasiliensis and Agaricus subrufescens; $7^{\text {th }}$ International conference on mushroom biology and mushroom products, INRA, Bordeaux.

Lowy B. 1952 - The genus Auricularia. Mycologia 44, 656-692.

Onyango BO, Palapala VA, Axama PF, Wagai SO, Gichimu BM. 2011 - Suitability of selected supplemented substrates for cultivation of Kenyan native wood ear mushrooms (Auricularia auricula). American Journal of Food and Technology 6, 395-403, Doi.org/10.3923/ajft.2011.395.

Rambaut A. 2012 - FigTree v1. 4.0. University of Oxford, Oxford, UK. http://tree.bio.ed.ac.uk/software/figtree (accessed 1 September 2019).

Rizal LM, Hyde KD, Chukeatirote E, Karunarathna SC et al. 2016 - First successful cultivation of the edible mushroom Macrolepiota dolichaula in Thailand. Chiang Mai Journal of Science 43, 959-971.

Royse DJ. 2010 - Effects of fragmentation, supplementation and the addition of phase II compost to 2nd break compost on mushroom (Agaricus bisporus) yield. Bioresource Technology101, 188-192, Doi 10.1016/j.biortech.2009.07.073.

Sajon SR, Sana S, Rana S, Rahman SM, Nishi ZM. 2018 - Mushrooms: Natural factory of antioxidant, anti- inflammatory, analgesic and nutrition. Journal of Pharmacognosy and Phytochemistry 7, 464-475.

Sun YX, Liu JC, Kennedy JF. 2010 - Purification, composition analysis and antioxidant activity of different polysaccharide conjugates (APPs) from the fruiting bodies of Auricularia polytricha. Carbohydrate Polymers 82, 299-304, Doi doi.10.1016/j.carbpol.2010.04.056.

Swofford DL. 2002 - PAUP* 4.0: phylogenetic analysis using parsimony (* and other methods). Sinauer Associates, Sunderland.

Thawthong A, Karunarathna SC, Thongklang N, Chukeatirote E et al. 2014 - Discovering and domesticating wild tropical cultivatable mushrooms. Chiang Mai Journal of Science 41, 134.

Thongbai B, Wittstein K, Richter C, Miller SL et al. 2017 - Successful cultivation of a valuable wild strain of Lepista sordida from Thailand. Mycological Progress 16, 211-223, Doi 10.1007/s11557-016-1262-0.

Thongklang N, Chen J, Bandara AR, Hyde KD et al. 2016 - Studies on Agaricus subtilipes, a new cultivatable species from Thailand, incidentally reveal the presence of Agaricus subrufescens in Africa. Mycoscience 57, 239-250, Doi 10.1016/j.myc.2016.02.003.

Thongklang N, Luangharn T. 2016 - Testing agricultural wastes for the production of Pleurotus ostreatus. Mycosphere 7, 766-772, Doi 10.5943/mycosphere/7/6/6.

Thongklang N, Sysouphanthong P, Callac P, Hyde KD. 2014 - First cultivation of Agaricus flocculosipes and a novel Thai strain of A. subrufescens. Mycosphere 5, 814-820, Doi 10.5943/mycosphere/5/6/11.

Ukai S, Kiho T, Hara C, Morita M et al. 1983 - Polysaccharides in fungi: XIII. Antitumor activity of various polysaccharides isolated from Dictyophora indusiata, Ganoderma japonicum, Cordyceps cicadae, Auricularia auricula-judae and Auricularia sp. Chemical and Pharmaceutical Bulletin 31, 741-744, Doi 10.1248/cpb.31.741.

Wang B, Jia DH, Gao J, Xian L, Tang LM. 2015 - Study on genetic differences and yields within Auricularia cornea mutants. Southwest China Journal of Agricultural Sciences 28, 28322834.

Wang XH, Zhang C, Fevereiro P, Zhang C. 2016 - Screening and characterization of Auricularia delicata strain for mushroom production under tropical temperature conditions to make use of rubberwood sawdust. Research Journal of Biotechnology 11, 26-37. 
Wang X, Lan Y, Zhu Y, Li S et al. 2018 - Hepatoprotective efects of Auricularia cornea var. Li. polysaccharides against the alcoholic liver diseases through diferent metabolic pathways. Scientific Reports 8, article 7574, Doi 10.1038/s41598-018-25830-w.

White TJ, Bruns T, Lee S, Taylor JW. 1990 - Amplification and direct sequencing of fungal ribosomal RNA genes for phylogenetics. In: Innis MA, Gelfand DH, Sninsky JJ, White TJ (Eds.), PCR protocols: A guide to methods and applications. Academic Press, San Diego, pp. 315-322.

Wu F, Yuan Y, Liu HG, Dai YC. 2014a - Auricularia (Auriculariales, Basidiomycota): a review of recent research progress. Mycosystema 33, 198-207.

Wu F, Yuan Y, Malysheva VF, Du P, Dai YC. 2014b - Species clarification of the most important and cultivated Auricularia mushroom "Heimuer": evidence from morphological and molecular data. Phytotaxa 186, 241-253, Doi 10.11646/phytotaxa.186.5.1.

Wu F, Yuan Y, Rivoire, Dai YC. 2015 - Phylogeny and diversity of the Auricularia mesenterica (Auriculariales, Basidiomycota) complex. Mycological Progress 14, 1-9, Doi 10.1007/s11557-015-1065-8.

Yuan Z, He P, Cui J, Takeuchi H. 1998 - Hypoglycaemic effect of water-soluble polysaccharide from Auricularia auricula-judae Quel. on genetically diabetic KK-Ay mice. Bioscience, Biotechnology, and Biochemistry 62, 1898-1903, Doi 10.1271/bbb.62.1898.

Zhang JP, Li XB, Yin Y. 2018b - A Method for Measuring the Degree of Fermentation of the Edible Mushroom Cultivation Substrate. Natural Resources 9, 355-360, Doi 10.4236/nr.2018.911022.

Zhang B, Miao R, Zhou J, Huang ZQ et al. 2017 - Effects of cultivating substrates with different nitrogen sources on agronomic traits, quality and production efficiency of Auricularia cornea. Journal of Southern Agriculture 48, 2210-2217.

Zhang X, Zhang B, Miao R, Zhou J et al. 2018a - Influence of temperature on the bacterial community in substrate and extracellular enzyme activity of Auricularia cornea. Mycobiology 46, 224-235, Doi 10.1080/12298093. 2018.1497795.

Zhao S, Rong C, Liu Y, Xu F, Wang S, Duan C, Chen J, Wu X. 2015 - Extraction of a soluble polysaccharide from Auricularia polytricha and evaluation of its anti-hypercholesterolemic effect in rats. Carbohydrate Polymers 122, 39-45, Doi 10.1016/j.carbpol.2014.12.041. 